\title{
KHARISIRIS DE AGOSTO EN EL ALTIPLANO AYMARA DE BOLIVIA
}

\author{
KHARISIRIS OF AUGUST ON THE AYMARA ALTIPLANO OF BOLIVIA
}

\author{
Gerardo Fernández Juárez ${ }^{1}$
}

\begin{abstract}
Agosto es en el altiplano aymara de Bolivia el tiempo sacrificial por excelencia donde las ofrendas ceremoniales, waxt'as y wilanchas sangrientas, junto con los personajes míticos que lo recorren, codifican un tipo de violencia ritual que alude a la percepción histórica de larga duración, tanto del tiempo como del espacio ceremonial, a la vez que contribuyen a la configuración de la propia identidad cultural de las sociedades aymaras contemporáneas.
\end{abstract}

Palabras claves: kharisiri, waxt' a, wilancha, agosto, aymaras.

August constitutes the most relevant sacrificial time on the Aymara plateau in Bolivia, where the ceremonial gifts, waxt'as and bloody wilanchas. Together with some mythical characters, codify a kind of ritual violence that refers to a long standing historical perception, related to both time and space of the ceremony and at the same time, contribute to the definition of the cultural identity of contemporary Aymara societies.

Key words: Kharisiri, waxt'a, wilancha, August, Aymaras.

Agosto es un período de gran importancia ceremonial en el altiplano aymara. Es el momento en que la tierra, pachamama, según cuentan los aymaras, se abre para recibir las ofrendas rituales que necesita para recuperar su vigor y fortaleza una vez transcurrido el invierno. Por eso le dicen lakani phaxi, "el mes que tiene boca". En agosto las familias aymaras realizan ofrendas ceremoniales en las chacras de cultivo y acuden a las cumbres de los cerros donde se encuentran los venerados achachilas, tutores ceremoniales de la montaña, a realizar las ofrendas y quemar las mesas rituales ${ }^{1}$ con la intención de satisfacer el apetito ceremonial que las montañas y la tierra padecen antes de iniciarse el nuevo ciclo productivo. Una vez efectuado el ritual, la tierra aparece simbólicamente preparada para que comiencen las labores de la siembra en todo el altiplano a partir de septiembre y octubre. La pachamama se abre el mediodía del primero de agosto. Es el momento óptimo para realizar las oblaciones rituales y expresar al mismo tiempo los ruegos y deseos que se espera obtener a lo largo del año. A la pachamama y a los achachilas hay que pedirles, con insistencia y comedimiento, que ayuden en el de- sarrollo del nuevo ciclo agrícola, que no falte la lluvia, que los cultivos crezcan y extiendan sus tonos multicolores en los meses de febrero y marzo, que el envidioso granizo no baile sobre las calaminas ni golpee las sementeras, que se vaya a otras comunidades, junto con la escarcha y la helada, sus flojos hermanos, a robar el fruto del trabajo humano. Todo depende del éxito de la ofrenda ceremonial, de la elaboración correcta y específica de los platos rituales, de la abundancia y calidad de las aspersiones ceremoniales y, por supuesto, de la acertada solicitud del oficiante ceremonial quien debe conocer las aficiones culinarias rituales de sus comensales sagrados y rogar por los intereses de sus representados con la apropiada cortesía ${ }^{2}$.

En tiempo de agosto es el propio mundo aymara el que aparece abierto a los encantos del pasado, aparecen los "tapados" y tesorillos coloniales, las ciudades de los antiguos chullpas y de los incas, así como el "oro vivo", animales de oro que se mueven produciendo fulgores azulados la víspera del primero de agosto. La tierra está abierta, el mundo aymara proyecta sus vísceras antiguas sobre la superficie (Fernández 1997).

$1 \quad$ Facultad de Humanidades de Toledo, Universidad de Castilla-La Mancha, Plaza de Padilla, 4; 45005, Toledo, España. Gerardo.FJuarez@uclm.es 
En tiempo de agosto son varias las manifestaciones rituales aymaras que incluyen diferentes oblaciones de sacrificio tanto cruentas como incruentas; tal vez, la más conocida sea la waxt'a o mesa que he comentado anteriormente, con una presencia extensa y amplia en las diferentes poblaciones andinas. Junto a la waxt'a y en ocasiones complementándola se produce en los sectores ganaderos del altiplano, con presencia de camélidos de altura, la wilancha o sacrificio de sangre de alguna llama o alpaca, preferentemente ${ }^{3}$. De igual forma, la wilancha presenta un acusado reconocimiento en contextos mineros para festejar el primero de agosto. Si atendemos a las narraciones orales que implican, desde la perspectiva aymara, a los seres cuya presencia en el altiplano y cuya interacción con sus pobladores se circunscribe de manera explícita aunque no excluyente al mes de agosto, podemos aventurar otras manifestaciones de violencia ceremonial que no afectan tan sólo a elementos rituales inocuos, sino a los propios seres humanos. Los propios cuerpos físicos de los pobladores aymaras son violentados en esta época por parte de varios personajes que acentúan sus correrías en este tiempo ceremonial ${ }^{4}$ (Fernández 1998a); uno de ellos aparece recorriendo el altiplano buscando víctimas a las que extraer grasa y sangre, es el kharisiri. Los materiales etnográficos que voy a presentar proceden tanto de comunidades aymaras de la Provincia Omasuyos, próximas al Lago Titicaca, como de la Provincia Ingavi del Departamento de La Paz.

\section{Kharisiri}

Kharisiri, kharikhari, lik'ichiri, khariri, son los términos aymaras más frecuentes que hacen alusión a la actividad violenta del personaje ${ }^{5}$, de ahí la expresión castellanizada que emplean algunos estudiosos del fenómeno, al definirlo como "degollador". El término lik'ichiri hace resaltar su carácter como recolector de grasa, $l i k^{\prime} i$. En quechua, en los dominios de Ayacucho se emplean los términos ñakaq y phistaku (Ansión 1989; Morote 1988 [1959]:153-177) ${ }^{6}$. La etnografía se ha ocupado de personajes parejos en el mundo hispano; conocidos son los "sacamantecas" españoles presentes en diversos lugares de la geografía hispana, así como sus equivalentes mediterráneos que han dado lugar incluso a la composición de modernas leyendas urbanas (Ortí y Sampere 2002).
En el caso de los Andes, se trate de un modelo hispano importado o no, los kharisiris aymaras adquieren un específico interés etnográfico. La forma de actuación de los kharisiris y sus características representativas están bien documentadas. Los kharisiris provocan el sueño en sus víctimas potenciales de diferentes formas, ya sea rezando plegarias católicas en sentido contrario al habitual, en especial el Padre Nuestro, tocando una campanilla o espolvoreando cenizas de difuntos y restos de la bolsa amniótica de los recién nacidos (Morote 1988:161). Ataca a los viajeros solitarios en los caminos a los que acecha a distancia; actúa fundamentalmente durante el mes de agosto $^{7}$ empleando un objeto o maquinita para recoger la grasa colectada de las víctimas, a la manera de termo. Igualmente se dice que emplea una jeringa para realizar la extracción, además es preciso tener en cuenta que al kharisiri le interesa tanto la grasa como la sangre de sus víctimas ${ }^{8}$. Su imagen tradicionalmente se ha relacionado con los sacerdotes y personas relacionadas con la Iglesia católica; en ocasiones era el mismo sacerdote, el que la mentalidad popular de los lugareños identificaba con el kharisiri o alguien que trabajaba con esta misión bajo su servicio. De hecho, la grasa humana indígena colectada, se decía, era empleada en la elaboración de todo un complejo elenco de objetos relacionados con el quehacer ceremonial del sacerdote (velas, campanas, santos óleos); otras versiones más modernas consideran que se emplea la grasa para elaborar jabón y cosméticos de los q'aras, los mestizos y blancos de las grandes ciudades, o para realizar aceites lubricantes en los ingenios mineros y en la puesta a punto de los automóviles; hay quien lo asocia al pago de la deuda externa (Albó 1999; Celestino 1998). El kharisiri viste de blanco y lleva el rostro tapado con su fardo o q'ipi para esconder su identidad.

Habitualmente la antropología andina ha relacionado el complejo del kharisiri con criterios de identidad o pertenencia, estableciendo las maneras de relación de los pobladores andinos con respecto a los que no lo son en términos de relaciones de poder expresadas a través del siniestro personaje ${ }^{9}$. Rivière (1991), Aguiló (1980) y Crankshaw (1990), entre otros investigadores, así lo han reflejado. Su figura ha sido considerada desde la perspectiva de la mediación ceremonial recientemente (Charlier 1998).

En la actualidad no sólo los sacerdotes y los extranjeros resultan sospechosos de ser kharisiri, 
según el modelo de relaciones de identidad que parecen puestas en juego entre los aymaras y los $q$ 'aras que son expresadas por el personaje que nos ocupa. La sospecha se ha extendido al interior de las comunidades aymaras, en especial sobre aquellos campesinos que rechazan los compromisos y obligaciones comunitarios; aquellos que próximos al entorno de las ciudades olvidan las normas comunitarias y se desentienden de sus responsabilidades, especialmente en la satisfacción de cargos públicos y rituales ${ }^{10}$. Por otro lado, se desconfía de los campesinos que se comportan al modo de la ciudad y que hacen pública ostentación de dinero, sin que se les reconozca actividad remunerada alguna. En la actualidad, el kharisiri está asentado en el seno de las propias comunidades; no faltan sospechas sobre tal o cual persona o familia a cuyos miembros se ha encontrado en actitud sospechosa de noche, por los caminos ${ }^{11}$.

La acusación de ser kharisiri resulta traumática para el afectado, aun a pesar de que no se pueda probar ni demostrar nada en su contra. El sospechoso sufrirá, a buen seguro, serios problemas de articulación social con el resto de familias y a la larga es posible que tenga que abandonar la comunidad a riesgo de perder la propia vida (Wachtel 1997). Resulta tan grave dicha acusación que los que poseen algo de dinero no dudan en ponerse en manos de abogados sin escrúpulos en los núcleos urbanos para conseguir algún papel oficial donde se acredite su inocencia (Fernández 1995:173).

El hecho de que la presencia del kharisiri se haya generalizado y que ya no sea formalmente un cura, o un extranjero, como antaño, sino que es gente como los propios aymaras, extiende igualmente el problema y las supuestas intenciones dañinas del personaje ${ }^{12}$.

El interés del kharisiri por la grasa parece que ha sido sustituido por la sangre ${ }^{13}$ humana, mucho más fácil de lograr con su "maquinita"; de hecho, le interesan ambos fluidos (Albó 1999; López 2001). El interés de la grasa humana corresponde a la grasa indígena que es la considerada de especial calidad, seca por la incidencia de la alimentación autóctona, repleta de técnicas que favorecen la deshidratación de los productos y que configuran cuerpos secos y resistentes ante la enfermedad como son conceptualizados los cuerpos de los indios, frente a los grasos, endebles y de poco aguante de los mestizos (Fernández 1998b; Gutiérrez 2002). La grasa y la sangre india son de gran valor siem- pre y cuando muera el afectado. Si la víctima no fallece los fluidos extraídos no valen nada; no pueden ser transformados en los productos que el sacerdote, los médicos, los ingenieros o los representantes del Estado precisan para sus diferentes fines. Si la víctima fallece, el propio kharisiri acudirá a la medianoche, sin que nadie le observe, a pedir perdón de rodillas, ante la tumba de su víctima. Solamente tras la muerte se hace visible en el cuerpo de la víctima la cicatriz que acredita el ataque de que ha sido objeto por parte del kharisiri.

La actuación del kharisiri está rodeada del más absoluto secretismo, tanto en lo que afecta a la relación que mantiene con sus víctimas como en la forma en que es preciso atender a los afectados por él. El yatiri, con la ayuda de los familiares del afectado, deberá actuar en secreto, sin revelarle nunca al paciente la dolencia que le aflige, si quiere tener alguna oportunidad de salvarlo.

$\mathrm{Al}$ empleo tradicional del cuchillo propio del degollador que aparece en los relatos de Morote (1988), le ha seguido una modernización tecnológica, que no hace sino reflejar la presión de la modernidad sobre las comunidades aymaras, en lo que a los útiles del kharisiri se refiere; de esta forma se le achaca el empleo de máquinas, tales como cámaras fotográficas, grabadoras o jeringas con las que extrae el sebo, o mucho más fácilmente la sangre de sus víctimas (Fernández 1999; Wachtel 1997).

La amenaza externa procede de lo "otro" cultural, étnica y tecnológicamente ajeno, así como de lo propio culturalmente distante, como es el caso de los comuneros que no se adecuan a las normas tradicionales y obligaciones imperantes en el entorno social del altiplano o al ejercicio del cambio cultural y de las mentalidades que promueven los propios estudiantes. La generalización de la amenaza del kharisiri en agosto hace que los propios campesinos recomienden no dormirse en los vehículos colectivos que viajan hasta la ciudad de La Paz, ya que el kharisiri puede estar a nuestro lado dispuesto para actuar.

Si en un principio era la institución eclesiástica la que concitaba las amenazas por el temor de los grupos indios sobre su poder, en la actualidad otros colectivos han tomado el relevo de la institución religiosa en esa relación asimétrica y debilitante con los aymara (Albó 1999). Tal es el caso de los médicos. Ningún colectivo como el sanitario, con su tendencia a los análisis sanguíneos y a la 
operación quirúrgica, la apertura excesiva de los cuerpos, resulta hoy tan próximo a la figura del kharisiri, circunstancia que limita notablemente sus posibilidades de atención y servicio (Fernández $1999)^{14}$. Los hospitales son considerados lugares nefastos donde los enfermos mueren y la atención personal deja mucho que desear; por otro lado, la amenaza de ser violentados los cuerpos, traficados los órganos internos y aprovechada la sangre para elaborar los diferentes tipos sanguíneos con la intención de comerciar con ellos, resulta patente. Junto a los médicos y representantes de ONGs, los propios estudiantes aymaras, portadores de nuevas mentalidades y modelos de cambio cultural, son considerados aliados de los kharisiris por los lugareños más ancianos (Fernández 2002).

Los kharisiris actúan durante todo el año, pero con especial incidencia, como hemos dicho, en agosto, particularmente la víspera del primero de agosto (Mendoza 1978:54), momento en que la tierra se abre. El primero de agosto, justo en el momento en el que la sangre de los campesinos es de mejor calidad, dada la variedad alimenticia que se consigue tras la cosecha, así como el mundo aparece abierto y expuesto a las características del pasado, el cuerpo de los seres humanos es violentado y abierto por las mañas del kharisiri extrayendo lo que debe permanecer oculto, la grasa y la sangre.

Para protegernos del kharisiri debemos mascar o llevar como amuleto ajo de Castilla, algún fragmento de "carne de ombligo", extenderse el propio sudor ${ }^{15}$, o simplemente revelar nuestra sospecha en voz suficientemente audible al encontrarnos con alguien por el camino, "¿no será kharisi$r i$ ?"; es decir, sacar al exterior y verbalizar lo que guardamos dentro en el caso de la sospecha oculta, un fragmento de carne seca de lo que siendo de naturaleza interna sale al exterior del cuerpo con el parto o bien mediante ajo de Castilla, por su fragancia y por su naturaleza foránea que afecta a la calidad de la grasa. Una triple exteriorización para prevenir la foraneidad más grave que puede sufrir nuestro cuerpo como expresión pública de su grasa corporal íntima empleada por el kharisiri en la elaboración de objetos de poder públicos tales como campanas, fármacos, tipos sanguíneos, hospitales o el pago de la deuda externa ${ }^{16}$. Lo privado que debe permanecer en el interior oculto es abiertamente mostrado para uso público por parte del kharisiri.
La dolencia originada por el kharisiri puede tratarse con una medicina específica que no es difícil encontrar en cualquier puesto de medicina tradicional, en los mercados y ferias rurales del altiplano. Consiste en un producto de aspecto viscoso cuya elaboración permanece en secreto, pero de precio muy elevado. En realidad se trata de un precio descabellado para la cantidad testimonial o ridícula que se ofrece al enfermo, siempre con su total desconocimiento sobre la medicina y la dolencia que padece. En este sentido la proporción resulta paralela a la grasa o la sangre que el paciente ha perdido. La cantidad que el paciente pierde en el ataque del kharisiri es testimonial, como lo es, igualmente, la dosis medicinal ingerida para su restitución. Existen otros tratamientos como el consumo de caldo de oveja negra y cuidados como evitar el consumo de productos frescos ${ }^{17}$ que pueden provocar la recaída del enfermo.

El tratamiento de la dolencia del kharisiri exigía antaño una serie de productos que en la actualidad ya no son eficaces. La razón es que entonces el kharisiri sacaba la grasa de la gente, pero no cualquier tipo de grasa sino el tejido conjuntivo denominado mesenterio, omento o redaño que en aymara se dice llikawara o iqara (Huanacu y Pawels 1998:126) y que aparece regularizado de forma genérica en el préstamo castellano "riñón"18. Como ahora saca la sangre, el tratamiento antiguo ha dejado de tener efecto; así al menos lo considera Macario Vargas, yatiri ${ }^{19}$ de Qurpa:

No, recién ahora. Antes que ya han sacado riñón, dice, sacado, dice tata cura, así dice. Ahora ya está sabiendo sacar sangre, recién no más. Antes riñón, ahora saca no más sangre. Los que hay enfermos que hemos visto, como aquí, o sea aquí, en la nalga o si no es en el pulmón, en la espalda inyección pica sin más[...]. Más antes también negro de oveja, su tela hay que sacar, con eso hay que poner no más para curar. Después parece que como nylon ha aparecido como nylonsito. Para vender sabe el cura ¿cómo será pues? Sabe el cura, ahora, no sabemos nosotros. Ahora recién ha recuperado con nylon oveja negra de tela. Riñón es pues. La oveja, cuando carneamos nosotros, su barriga es como riñón; ese saca. Después con calentito, pone, como emplaste. Con eso no más ha recu- 
perado dice los abuelos no más. Con eso no más ha curado dice. Ahora ya carneamos la oveja, ahora, sacando su riñón de la oveja con calorcito pone... no, ¡no sana!

El objeto tradicional de deseo del kharisiri era la grasa del mesenterio, el "riñón" o redaño de los seres humanos, ese tejido pleno de vasos linfáticos y células adiposas que unen los intestinos y el estómago con el abdomen. De hecho, se emplea todavía en algunas prácticas terapéuticas la "tela" del mesenterio de las ovejas negras en el tratamiento del mal atribuido al kharisiri. La llikawara de la oveja debe colocarse caliente sobre el lugar afectado del paciente con incienso blanco hasta que el tejido se seque por completo sobre su cuerpo (Huanacu y Pawels 1998:126; Rivière 1991:26).

El redaño constituye uno de los elementos esenciales en la recuperación del afectado por el mal del kharisiri. A pesar de la apreciación de Macario vinculando su empleo al pasado, todavía se utiliza en la actualidad. Como vemos para el yatiri Macario el empleo de la llikawara estaba relacionado con la actuación del sacerdote en su acepción de kharisiri y su interés añejo por la grasa de los adentros de los seres humanos, su interés precisamente por el redaño inspirado bajo el préstamo "riñón". Veamos otra versión de un maestro kallawaya, Severino Vila:

El kharisiri tiene su presión... iphucha! muy caloraso siente... calor, tiene diarrea, no tiene valor, en la cama se acuesta, ya no se puede levantar más. Para eso nosotros, ¡cosa sencilla! No es mucho. Podemos preparar grasa o una oveja negra. Agarramos, rápidamente, el panza le abrimos, la grasa, lo que complementa a la panza, su grasa ese hay que sacar, su telita y todo... lik'i decimos nosotros en quechua. Entonces eso "k'aj” colocando "aquí me duele", "k'aj" le hacemos colocar, después huevo batido blanco no más, también puede ser eso, también puede limpiar con los cuatro huevos o también puede tomar, tomadito un huevo, pero sin azúcar nada, eso se llama curación de los kharisiris. Estos temas raras veces me llegan, pero nuestros abuelos nos contaron. Esas cosas, sí, una vez cada unos cuantos años, una vez escuchamos; a los dos años... ¡una vez! Así pasa. Hay también otra forma. Prepara habas rojo, sebo de llama, su líquido que bota se prepara.

En castellano "redaño" equivale a lo más interno y de más valor que posee la persona. " $i$ Tiene redaños!", se dice de la persona con bríos, con ánimo y valentía ${ }^{20}$. El redaño se asocia por tanto con el coraje y el valor, es decir, con las entidades anímicas de los jaqi aymaras ${ }^{21}$. Uno de los rasgos del doliente afectado por el mal del kharisiri es la pérdida de bríos y valor para enfrentarse a la vida. La supuesta pérdida de sangre o grasa recluye a la víctima en su casa. El afectado carece de valor, el principal recurso energético y vital que posee la vida humana representado en la gordura, la grasa y la sangre (Bastien 1986; Szeminski 1987). La grasa del redaño parece apropiada para reflejar materialmente las "sombras" de los jaqi aymaras. La grasa del redaño, como el propio Macario nos ha explicado, supone el pasado y, a la vez, lo más interno y valioso de la persona.

La dolencia del kharisiri se trata de diferentes formas en el altiplano; puede ser con ese producto de aspecto graso, tremendamente caro, que en pequeñas dosis se ofrece al enfermo, sin que este identifique para qué tiene que tomar dicha medicina. El yatiri Macario y su mujer Cipriana experta en hierbas y farmacopea tradicional elaboran su propia medicina para el mal del kharisiri, adecuándose al hecho novedoso y reciente de su preferencia por la sangre humana. Recordemos que el tratamiento tradicional, basado en el interés del kharisiri por la grasa, ya no resulta eficaz.

Si te mueres ya sale, han picado. Marca sale. Cuando muere... ¡ya está! sale clarito su marca. Ya sabe la gente, habla pues, kharisiri ha estado sacando... ¿Como? Para eso no más estoy preparando la medicina. Hay que hervir una ollita de wayruro ${ }^{22}$ con Nicolás $T^{\prime}$ ant ' $a$, Altamisa ${ }^{23}$, Andres waylla ${ }^{24}$, Qutu-qutu ${ }^{25}$, hembra y macho; dos clases, urqu qutu-qutu, qhachu qutu-qutu. Después este... "solda con solda" ${ }^{26}$ después, este... de wawa, su ombligo ese poquito no más poner.

Como vemos, entre los productos utilizados por Macario destacan diversas especies herbáceas locales asociadas con los acuíferos del altiplano, 
así como especies de carácter ceremonial como el wayruru y el pan de San Nicolás, presente igualmente en el ritual de recuperación de las ch'iwi y la carne del ombligo.

Otros tratamientos eficaces en el tratamiento del mal del kharisiri, además de las recomendaciones del yatiri Macario Vargas y del kallawaya Severino Vila, incluyen la ingestión de sopas grasas, especialmente caldo de oveja, huevo batido; introducir al enfermo en el interior de la panza de una vaca negra e incluso la ingestión diaria de vino con hostias (Huanacu y Pawels 1998:127). Estos procedimientos terapéuticos pretenden recuperar los fluidos perdidos mediante el aprovechamiento de la grasa de oveja negra en cataplasma, la sangre de gallo negro bebida y la ingestión de alimentos caldosos y cálidos. El alegato a la eucaristía profana que reproduce el enfermo durante unos días con el tratamiento de vino y hostias, trata en definitiva sobre el cuerpo y la sangre de Cristo, es decir, lo dañado por el kharisiri que se trata de restituir a la víctima potenciando su ingestión diaria.

Evitar productos alimenticios "frescos" contrasta con el carácter cálido de la enfermedad provocada por el kharisiri. A pesar de esta variable térmica del calor que pareciera recomendar precisamente alimentos frescos para equilibrar la temperatura corporal, el carácter del afectado por la dolencia del kharisiri no es cálido, sino socialmente frío como demuestra su abulia generalizada, flojera y dejadez. El consumo de alimentos cálidos pretende restituir tanto el fluido como la vitalidad perdida tras el ataque perpetrado por el kharisiri.

\section{El Kharisiri y el Estado Boliviano}

La violencia propiciada por Sendero Luminoso en los años ochenta del pasado siglo y las masacres resultantes de los enfrentamientos con el ejército han sido explicadas, cuando no justificadas por los lugareños quechuas del sector de Ayacucho, por la presencia y actuación del ñakaq o del phistaku; lo mismo respecto a la virulencia de las ofensivas senderistas en Lima que dieron lugar a una variante del fenómeno, como fueron los "sacaojos", provocando una verdadera histeria en las barriadas más populares de Lima (Ansión 1989). En las alturas bolivianas de Potosí, noticias aparecidas en periódicos y noticieros de radios sensacionalistas, sobre supuestos avistamientos de ovnis dieron lugar a histeria no menos significativa entre los pobladores andinos de la zona quienes vinculaban la noticia con el kharisiri, realizando patrullas de autodefensa para protegerse de la nefasta influencia del personaje (Aguiló 1980).

El gobierno de Sánchez de Lozada del Movimiento Nacionalista Revolucionario (MNR) impulsó, en los años noventa del pasado siglo, tres leyes fundamentales sobre las que gravitó buena parte de la tensión política y social de la legislatura, a saber: La Ley de Participación Popular, la Ley de Reforma Educativa y la Ley de Capitalización. Las tres normas supusieron una formalización de cambios administrativos y jurídicos que afectaron a las comunidades aymaras en diferente forma, dando lugar a no poca confusión. El reconocimiento de las lenguas nativas locales en la educación formal, la decisiva intervención de los municipios y ayuntamientos para la concesión de ayudas a los proyectos de desarrollo y las formas de adjudicación de las empresas más rentables del Estado a los nuevos socios privados provocaron no pocos sofocos en las comunidades rurales del altiplano, cuyo ámbito de aplicación se entendía poco menos que como una expropiación de terrenos de cultivo y totorales de pesca, sin olvidar el enfrentamiento político por el acceso a los municipios y el apoyo a los proyectos de desarrollo o los traumas derivados de la farragosa terminología administrativa que convertía de golpe y porrazo a las comunidades en OTB (Organizaciones Territoriales de Base). En la actualidad, todavía colean las decisiones del INRA y el temor de los campesinos a tener que pagar impuestos al Estado por sus posesiones agrícolas.

La delicada situación de un bien patrimonial indígena como es la hoja de coca con la política de erradicación de cocales impulsada por las distintas administraciones norteamericanas en aras a la permanente amenaza de descertificación de Bolivia como país preferente en la canalización de la ayuda internacional, que ha dado lugar a la militarización de extensas zonas de los yungas y sobre todo del Chapare en Cochabamba y del parque IsiboroSécure, zona de ampliación de las actividades del narcotráfico; la política alimentaria y de donación de alimentos a cambio de trabajo, las variables de género y la constancia política de Bolivia como República multicultural, contenido que refleja la propia Constitución boliviana, con el reconocimiento periódico al impulso necesario de pautas de desarrollo intercultural en el dominio educativo, de la salud, en la información periodística, etc., 
que mejoren de forma sustancial la convivencia interna de los bolivianos superando situaciones anquilosadas de extrema injusticia social (Albó 1999), constituyen retos importantes para la convivencia diaria de los bolivianos que serán reflejo del programa de la próxima Constituyente.

Los kharisiris menudean en sus apariciones, al abrigo de toda esta situación crítica de tremenda confusión conceptual y económica, "haciendo su agosto", en lo que a vidas humanas se refiere, tanto en la localidad de Achacachi, cabecera municipal, como en su entorno ${ }^{27}$, dando sentido al caos informativo y sobre todo de carácter comprensivo a los cambios que impulsa el Estado boliviano ${ }^{28}$.

Así las cosas, parece que cuando se toman decisiones, lejos del entorno comunitario aymara y de sus órganos colegiados que regulan la vida colectiva, que pueden alterar o modificar la vida de los propios pobladores aymaras, al margen de su propia capacidad de control y decisión, el retorno de los kharisiris y su violenta irrupción en las vidas de la gente parece un hecho consumado. Las innovaciones propuestas en época de crisis social y penuria económica, sin consultar previamente a las colectividades interesadas, que afecten la vida cotidiana de las comunidades, pueden dar lugar a la presencia del temible personaje. Los kharisiris parecen de esta forma señuelos del cambio sociocultural en el altiplano, al igual que en otros sectores de los Andes (Wachtel 1997:82). Cualquier tipo de circunstancia que el ámbito comunitario de decisión no pueda satisfacer y controlar, viéndose a su vez afectado negativamente por ella, da con el kharisiri sobre el escenario social. El kharisiri es el portador de las innovaciones no concertadas (curas, médicos, ingenios, ONGs, estudiantes, etc.), responsable de las mismas cosechando la sangre de los comuneros a cambio de las nueva propuestas. El kharisiri "abre" el cuerpo físico y social de los grupos aymaras del altiplano promoviendo cambios generalmente no deseados por la comunidad, cambios pensados desde instancias ajenas a la estructura comunitaria ${ }^{29}$.

En España y en la tradición europea, el "sacamantecas" tiene como objetivo fundamental a los niños pequeños, a los que se amedrenta con su figura para que se comporten según la norma establecida; en este sentido, el "sacamantecas" es un aliado de la estructura familiar para canalizar la pauta de comportamiento adecuada en los más pequeños; podríamos considerarlo, junto a otros personajes afines, como un vehículo de endoculturación. En el altiplano, sin embargo, la amenaza del kharisiri se extiende a toda la sociedad y son los adultos, no los niños, su objetivo principal; de hecho, las wawas lactantes no tienen todavía la calidad de sebo que el kharisiri anhela, no están suficientemente hechos, por lo que no resulta contradictorio que les desprecie como posibles víctimas ${ }^{30}$. Frente a la tendencia al conservadurismo del "sacamantecas" español contrasta el valor progresista del kharisiri aymara portador de los cambios que el Estado y otras instituciones ajenas al dominio aymara pretenden imponer sin su consentimiento ${ }^{31}$. Mientras el "sacamantecas" ayuda a la comunidad familiar a mantenerse en las pautas tradicionales, por eso persigue a los niños que no se comportan según las reglas, el kharisiri aymara introduce y modifica dichas pautas a través de los nuevos mecanismos que el cambio cultural ofrece, por eso persigue a los adultos, los mantenedores de la costumbre y de la memoria social, los futuros formadores de niños. El kharisiri no victima a las wawas porque las necesita encarecidamente en el proyecto de cambio gestado por el Estado quien los forma en las escuelas seccionales presentes en el altiplano; así cobra sentido el parecer del yatiri Macario Vargas achacando a los estudiantes su talante como modernos kharisiris que chupan junto a la grasa y la sangre de los cuerpos la memoria social y las pautas de comportamiento que dan sentido a la estructura comunitaria local ${ }^{32}$.

En España el "sacamantecas" es corrector aliado de los padres, mientras que en los Andes del sur, en los dominios rurales, es aliado del Estado, encarnando los valores más traumáticos y los que peor plantean la supervivencia de las comunidades rurales; lo prohibido, fundamentalmente el crédito absoluto al individualismo y a la falta de reciprocidad para con su grupo de referencia. Pero además el kharisiri compromete al propio concepto de persona, al aparecer la grasa humana y la sangre entre sus objetivos de cuestación forzada, elementos de gran significación ritual en la tradición de las poblaciones andinas. El concepto de persona alude a la propia historia social y a la memoria colectiva que las poblaciones andinas reproducen en su entorno, tanto físico como comunitario. Las acechanzas del kharisiri no sólo ponen en peligro el cuerpo físico, sino la estabilidad colectiva, los valores fundamentales ligados a la reciprocidad en los dominios rurales y, por tanto, la forma de ser y 
de estar en el mundo, clara referencia al impacto de la modernidad y el efecto del cambio cultural que las poblaciones andinas continúan padeciendo de forma asimétrica e incontrolada en los albores del siglo XXI.

Mientras los "sacamantecas" españoles hace tiempo que permanecen encorsetados en el dominio de la imaginación, los cuentos y las consejas de abuelos, como remedio extremo con el que atemorizar a los niños, sus "colegas" andinos caminan por el campo, portafolio en mano por los despachos de abogados, las oficinas dedicadas al desarrollo, las consultas de las postas sanitarias y hospitales o las escuelas, atendiendo como buenos funcionarios las necesidades estatales de sangre india y provocando el más pavoroso de los horrores en el corazón del mundo aymara.

Cierta moraleja parece desprenderse de este asunto de los kharisiri. La moraleja que emana de la amenaza del kharisiri en las sociedades aymaras del altiplano es que resulta contraproducente y peligroso alejarse de la "madre", tal y como recomendaban en su tiempo los "sacamantecas" hispanos, de la tierra, de la memoria colectiva, de los usos tradicionales que tan buen resultado han dado a los campesinos aymaras, quizá no para prosperar individualmente según las pautas occidentales, pero sí para defender sus intereses comunes. La enfermedad del kharisiri se cura en la discreción del hogar, practicando la máxima cerrazón del cuerpo familiar sobre la víctima, ocultándole incluso al propio enfermo la causa de su enfermedad; el mejor talismán para evitar los ataques constituye la carne de ombligo, vínculo entre el hijo y la madre, es decir, entre el hijo y la memoria histórica del grupo con sus pautas y normas de comportamiento. La dolencia del kharisiri no se cura en el hospital, el médico nada sabe del kharisiri, al menos terapéuticamente, no otorgándole credibilidad alguna, el mal del kharisiri se cura en la intimidad de la casa, igual que los problemas comunitarios se resuelven, al margen de las directrices del Estado, en los cabildos y asambleas comunitarias donde cada comunero expone públicamente su parecer hasta alcanzar consenso; cuando las instituciones estatales y sus representantes pretenden entrar en el cuerpo social aymara, como el kharisiri penetra en la vena del comunero dormido, a traición, proponiendo innovaciones arriesgadas, la única forma de subsistir radica en vencer el ataque foráneo cerrando filas sobre la unidad física y so- cial de la comunidad. Son los propios comuneros los que tienen el derecho de manejar y decidir sobre su propio futuro, son ellos los que deben decidir sobre su cuerpo físico y social y sobre su mañana en el tipo de relaciones que precisan establecer con el Estado boliviano. La amenaza de los kharisiris ejemplifica la dificultad existente hoy en el entramado correcto de dichas relaciones, dificultades inscritas en la propia biografía histórica del Estado boliviano. Si los aymaras y otros grupos andinos no dudan en descalificar a los representantes institucionales del Estado como kharisiris, a su vez, los representantes del poder criollo señalan a los grupos indios del altiplano como "bárbaros" y "salvajes", a sus especialistas rituales como "brujos" y al colectivo indio como "caníbales"33. En definitiva, unos y otros considerados respectivamente como depredadores y amenaza para una propuesta social de convivencia lejos todavía, a pesar de los esfuerzos realizados, de configurar el marco intercultural propicio que dé cabida a los legítimos intereses de todos los bolivianos.

La candente cuestión del kharisiri no hace sino reforzar la consideración final de la variable étnica y las relaciones interculturales en Bolivia. Por fin, los grupos autóctonos encuentran mejores cauces para expresarse y representarse a sí mismos sin necesidad de intermediarios. La lucha de las poblaciones indígenas de Bolivia y América Latina, en general, incluye el reconocimiento de los modelos de reproducción y construcción de sus respectivas identidades, en los que los componentes culturales, lingüísticos, las peculiaridades productivas y sistemas de vida, así como las denominaciones colectivas, han constituido aspectos importantes de las reivindicaciones indígenas. Siempre nombrados por los "otros", de forma despectiva como "indios" en tiempos de la Colonia y la República; "campesinos" tras la revolución de 1952 y finalmente, tras el reconocimiento político de la diversidad cultural boliviana, significados como aymaras, miembros de las Naciones Originarias de Bolivia en igualdad de derechos con el resto de poblaciones acogidas a la Carta Magna boliviana. Cabe esperar que una situación de mayor equilibrio en el reconocimiento de la pluralidad cultural de Bolivia y el impacto de las estrategias de desarrollo intercultural en esferas diversas de la vida social boliviana ayuden a mejorar la convivencia y el sentido de solidaridad entre todos los bolivianos. 


\section{Referencias Citadas}

Aguiló, F.

1980 El lik'ichiri: Un signo de autodefensa cultural. Simposio Simbología Andina, Cochabamba.

Albó, X.

1979 Achacachi. Medio Siglo de Lucha Campesina. CIPCA, La Paz.

1999 Introducción. En Médicos y Yatiris. Salud e Interculturalidad en el Altiplano Aymara, G. Fernández, pp.13-19. Ministerio de Salud y Previsión Social OMS/CIPCA/ESA, La Paz.

Albó, X., T. Greaves y G. Sandoval

1983 Chukiyawu. La Cara Aymara de La Paz, III, Cabalgando entre dos Mundos. CIPCA, La Paz.

Ansión, J., editor

1989 Phistacos. De verdugos a Sacaojos. Tarea, Lima.

Bastien, J.

1986 Etnofisiología andina. Evidencia lingüística, metafórica, etiológica y etnofarmacológica para conceptos andinos sobre el cuerpo. Arinsana 1:5-24.

Castellón, I.

1997 Abril es Tiempo de Kharisiris. Campesinos y Médicos en Comunidades Andino-Quechuas. Editorial Serrano, Cochabamba.

Celestino, O.

1998 Transformaciones religiosas en los Andes peruanos.

2. Evangelizaciones. Gaceta de Antropología 14:14-25.

Crankshaw, C. 1990 ¿Por Qué el Susto? Mimeo, La Paz.

Charlier, L.

1998 Histoire d'un singulier vampire masqué: le kharisir. Lazos "Etudes" 1:55-70.

Fernández, G.

1995 El Banquete Aymara: Mesas y Yatiris. HISBOL, La Paz. 1996 El mundo abierto: Agosto y Semana Santa en las celebraciones rituales aymaras. Revista Española de Antropología Americana 26:205-229.

1997 Entre la Repugnancia y la Seducción: Ofrendas complejas en los Andes del Sur. Centro de Estudios Regionales Andinos "Bartolomé de las Casas", Cuzco.

1998a Iquiqu y anchanchu: Enanos, demonios y metales en el altiplano aymara. Journal de la Société des Américanistes 84:147-166.

1998b Enfermedad, moda y cuerpo social en el altiplano aymara: un boceto de inspiración colonial sobre modelos de identidad en los Andes. Revista Española de Antropología Americana 28:259-281.

1999 Médicos y Yatiris: Salud e Interculturalidad en el Altiplano Aymara. CIPCA/OMS/ESA, La Paz.

2000 Creencias populares y prácticas religiosas en España y América: Sacamantecas en los Andes del Sur. En Religiosidad Popular y Modelos de Identidad en España y América, editado por J.C. Vizuete y P. Martínez-Burgos, pp. 281-324. Universidad de Castilla-La Mancha, Cuenca. 2002 Aymaras de Bolivia. Entre la Tradición y el Cambio Cultural. Editorial Abya-Yala, Quito.

2004a Yatiris y Ch'amakanis del Altiplano Aymara. Testimonios, Sueños y Prácticas Ceremoniales. Editorial AbyaYala, Quito. 2004b Ajayu, animu, kuraji, La enfermedad del susto en el altiplano de Bolivia. En Salud e Interculturalidad en América Latina. Perspectivas Antropológicas, coordinado por G. Fernández, pp. 279-303. Editorial Abya-Yala, Quito.

Girault, L.

1987 Kallawaya. Curanderos Itinerantes de los Andes. Investigación sobre Prácticas Medicinales y Mágicas. UNICEF/OPS/OMS, La Paz.

1988 Rituales en las Regiones Andinas de Bolivia y Perú. CERES / MUSEF /QUIPUS, La Paz.

Gutiérrez, M.

2000 Introducción. En Sustentos, Aflicciones y Postrimerías de los Indios de América, editado por M. Gutiérrez, pp. 714. Casa de América, Madrid.

2002 Interioridades. En Según Cuerpos: Ensayo de Diccionario para Uso Etnográfico, editado por M. Gutiérrez, J.A. Flores, M. García, J. López y P. Pitarch, pp. 83-141. Editorial Cicón, Badajoz.

Huanacu, B.N. y G. Pawels

1998 El kharisiri: Lik ichiri y /o sirksuri. Eco Andino 6:121-146.

Lévy-Bruhl, L.

1985 [1927] El Alma Primitiva. Península, Barcelona.

López, J.

2001 Comida y bases de la identidad aymara en el altiplano de Bolivia. En Alimentación y Sociedad en Iberoamérica y España. Cinco Etnografías de la Comida y la Cocina, editado por J. López, pp. 97-120. Universidad de Extremadura, Cáceres.

Mendoza, S.

1978 Salud y enfermedad en la cultura aymara. Boletín del Instituto de Estudios Aymaras 2:40-60.

Molina, C. de

1989 [1581] Relación de las fábulas i ritos de los ingas. En Fábulas y Mitos de los Incas, editado por H. Urbano y P. Duviols, pp. 50-150. Editorial Historia 16, Madrid.

Molinié, A.

1991 Sebo bueno, indio muerto: La estructura de una creencia andina. Bulletin de l'Institut Français d'Etudes Andines 20:79-92.

Morote, E.

1988 [1959] El Nakaq. En Aldeas Sumergidas. Cultura Popular y Sociedad en los Andes, editado por E. Morote, pp. 153-177. Centro de Estudios Regionales Andinos "Bartolomé de las Casas", Cuzco.

Ortí, A. y J. Sampere

2002 Leyendas Urbanas en España. Editorial Martínez Roca, Barcelona.

Pedrosa, J. M.

1999 Judíos en la literatura española. IX Curso de Cultura Hispanojudía y Sefardí. Toledo.

Rivière, G.

1991 Lik'ichiri y kharisiri. Bulletin de l'Institut Française d'Etudes Andines 20:23-40.

Sppeding, A.

1996 Espacio, tiempo y lenguaje en los Yungas. En Las Armas de la Utopía, editado por A. García, pp.247-280. UMSA, La Paz. 
1992 Almas, anchanchus y alaridos en la noche: El paisaje vivificado de un valle yungueño. En Etnicidad, Economía y Simbolismo en los Andes, compilado por S. Arze, pp. 75146. HISBOL- IFEA- SBH-ASUR, La Paz.

2005 Sueños, Kharisiris y Curanderos. Editorial Mama Huaco, La Paz.

Szeminski, J.

1987 Un Curaca, un Dios y una Historia. Instituto de Ciencias Antropológicas, San Salvador de Jujuy.

Urbano, $\mathrm{H}$.

1988 Introducción, En Aldeas Sumergidas, editado por
E. Morote, pp. 1-20. Centro de Estudios Regionales, Andinos "Bartolomé de las Casas", Cuzco.

Wachtel, N.

1997 Dioses y Vampiros: Regreso a Chipaya. Fondo de Cultura Económica, México.

Zalles, J.

1999 Complementación de las dos medicinas en el campo. Médicos y yatiris. Salud e Interculturalidad en el Altiplano Aymara, editado por G. Fernández, pp. 229-241. CIPCA /OMS/ESA, La Paz.

\section{Notas}

1 Ofrendas complejas constituidas por ingredientes de diferente naturaleza (vegetales, animales, dulces) con sus correspondientes expresiones sensibles y diferenciadas, que constituyen dones alimenticios de los seres tutelares del altiplano (Girault 1988; Fernández 1995, 1997).

2 En la ciudad de La Paz sucede algo semejante, si bien los residentes aymaras de El Alto y de las barriadas populares de la hoyada adaptan el contexto ceremonial de agosto a las específicas características de la vida citadina; el mes de agosto supone un hervidero de propuestas ceremoniales que tanto yatiris como kallawayas cumplimentan con eficacia a los diferentes grupos sociales y culturales de la ciudad. El dominio mestizo y latino comparte lógicas semejantes a las de los residentes aymaras o quechuas en agosto, de tal forma que profesionales liberales, farmacéuticos, militares, arquitectos y abogados, no dudan en ch'allar sus negocios y hacer sus correspondientes mesas con la intención de que los negocios fructifiquen y cristalicen en solventes carteras de clientes. Indudablemente la "pega", el trabajo, es una de las prioridades en las solicitudes rituales de los residentes aymaras urbanos (Albó et al. 1983).

3 En agosto de 1995 los pobladores de la zona lacustre del Lago Titicaca comentaban la realización de una wilancha humana en la persona de una pastorcita aymara originaria de la localidad de Warina que, al parecer, habría sido entregada en el altar de los Ispa Awichus del Cerro Pachjiri. El hecho fue motivo de alguna pequeña información en los noticieros televisivos más truculentos de la televisión boliviana. Mientras los periodistas hablaban de crimen, los pobladores aymaras empleaban el término "pagancia", en alusión a su carácter ceremonial.

4 El Anchanchu es uno de los seres maléficos especialmente dañinos y perniciosos que aparecen en el mes de agosto; dueño del "oro vivo" es responsable de causar la locura entre sus víctimas adoptando formas diferentes (Fernández 1998a).

5 Kariña, cortar.

6 El estudio de estos peculiares "sacamantecas" presentes en los Andes del Sur ha dado lugar a una abundante y contrastada etnografía (Albó 1999; Fernández 1996; Molinié 1991; Rivière 1991; Wachtel 1997) que discrepa sobre su posible origen, amerindio para unos, español para los otros. Las pruebas en favor del origen hispánico del personaje se basan en algunas apreciaciones presentes en las crónicas de la Colonia donde se refleja el asombro que provocaba en los indígenas el interés de los españoles por el unto de los indios fallecidos a los que sacaban el sebo para curar sus propias heridas (Molina 1581). Conocemos igualmente la maledicencia cometida contra la orden betlemítica a principios del siglo XVIII en su interés por fundar un hospital en el Cuzco y el rumor maléfico que les describe como degolladores interesados en el sebo de los indios para satisfacer las boticas de la corona española (Morote 1988:168).

7 En la localidad kallawaya de Curva, me comentaron que los kharisiris aparecen tanto en agosto como durante la época de la cosecha, lo que parece concordar con los datos de Ayopaya en Cochabamba, recogidos por Iván Castellón (1997) que hace de abril época de kharisiris en los valles, a pesar de constituir una institución cultural eminentemente altiplánica.

8 Parece existir cierto acuerdo en la consideración del interés de la grasa humana como algo antiguo para los kharisiris quienes parecen detentar en la actualidad un mayor interés por la sangre de los pobladores aymaras, al menos en las comunidades ribereñas del Lago Titicaca.

9 Sin embargo esta aplicación étnica que parece definir al "sacamantecas" como la expresión refinada de la alteridad étnica respecto a lo indio encuentra igualmente su acomodo y expresión adecuada en la literatura española donde son los "judíos", los moralmente "otros", los acusados de ser "sacamantecas" por parte de los cristianos (Pedrosa 1999).

10 La sospecha y el rumor actúan en la definición comunitaria del kharisiri reafirmando la naturaleza del personaje y resaltando sus rasgos más sobresalientes (Sergio Guarisco comunicación personal, 1993).

11 Recuerdo en la comunidad de Tuqi Ajllata Alta, cerca de Achacachi, la insistencia en aplicar a una de las familias de la comunidad la sospecha de ser kharisiris simplemente por el servicio de contratista de mano de obra que uno de los comuneros cumplía respecto a una hidroeléctrica que se estaba construyendo en los yungas. La capacidad autoritaria y la decisión de definir quién se iba a beneficiar de ese dinero adicional y quién no, resultó suficiente para levantar el bulo de su connivencia con los ingenieros de la hidroeléctrica y su talante como kharisiri.

12 En el caso de los sacamantecas españoles su interés exclusivo son los niños. Buscan a los niños en los relatos para sacarles la grasa, la asadura y la sangre sirviendo de modelo ejemplar en el comportamiento social de los pequeños. Las prédicas de los clérigos españoles en las crónicas co- 
loniales no hacen sino resaltar una y otra vez la ingenuidad, candidez e inocencia de los indios, como si fueran niños, razón que tal vez justifique la extensión del interés del kharisiri por todos los segmentos poblacionales de las sociedades aymaras. En el altiplano, la cuestión del kharisiri no es cosa de niños, ni mucho menos, sino un problema vivido con especial angustia e intranquilidad por todos aquellos que se encuentran implicados en él, tanto los enfermos como los supuestos kharisiris, señalados por la comunidad.

13 Este aspecto de la sangre y la grasa, junto con la actualizada presencia de kharisiris que ya no adquiere una diferenciación étnica marcada con respecto a sus propias víctimas indígenas muestra, de forma diacrónica, la importante vitalidad que presenta esta institución y su adaptación continua al proceso de cambio de las propias comunidades aymaras del altiplano. Igualmente esta aparente sustitución en las apetencias del kharisiri de la grasa por la sangre, según algunos pobladores aymaras, sugiere significativas apreciaciones identitarias y cognitivas a las que voy a referirme en otro futuro estudio.

14 De hecho, una de las denominaciones más frecuentes que los aymaras del lago Titicaca emplean para referirse al kharisiri es "operador" equivalente al castellano "cirujano", circunstancia que dificulta en gran medida cualquier tipo de planteamiento intercultural en salud (Fernández 1999).

15 Así lo refleja Julián López (2001:114); el sudor y el ajo de Castilla afecta a la propia calidad de la grasa humana, haciéndola poco apetecible para el kharisiri.

16 Es una creencia común en los Andes el hecho de que las campanas fundidas con grasa humana suenan mejor. Este tipo de consideraciones antiguas aparecen reflejadas en la reordenada configuración de leyendas urbanas relacionadas con el hombre del saco y toda una pléyade de personajes que buscan la grasa y la sangre de los infantes para lubricar ingenios mecánicos e industriales (Ortí y Sampere 2002; Urbano 1988).

17 El sistema cálido-fresco presente en las concepciones andinas y aymaras de la enfermedad no obedece tan sólo a criterios térmicos sino fundamentalmente simbólicos (Gutiérrez 2000).

18 El interés de la grasa de los riñones como fluido vital y su vinculación con la representación individualidad y el alma de los seres humanos, no resulta exclusivo de las poblaciones andinas; Lévi Bruhl (1985[1927]:107) documenta su presencia entre grupos australianos. En una de las cartas de los pioneros de Victoria indica: "La más terrible de sus supersticiones es que creen que el hombre sólo muere cuando es matado, que cuando está enfermo su cuerpo está abierto y se ha atacado sus riñones y su grasa lo que le causa la muerte; y que sólo la grasa o los riñones de otro pueden curar la enfermedad. Creen también que puesto que los riñones y su grasa constituyen la vida del hombre, el hecho de comerlos dobla la fuerza y el vigor del que los come. Por esto nunca matan un "negro salvaje" -pues así los llaman- sin recoger esta parte de su cuerpo".

19 Yatiri, "sabio". Especialista ritual aymara diestro en la consulta de hojas de coca y en la elaboración de ofrendas rituales (Fernández 2004).

20 Información que debo al profesor Manuel Gutiérrez Estévez. Las interioridades del cuerpo son conceptualizadas como valiosas y relacionadas con el pasado en diferentes poblaciones amerindias (Gutiérrez 2002).

21 Tres son las entidades anímicas de los jaqi aymaras: de adentro hacia fuera y de mayor a menor importancia: ajayu, animu y kuraji. Son denominadas kimsa ch' iwi, las tres sombras que de hecho se ven afectadas con su pérdida provocando aflicciones y enfermedades a la persona tras el ataque del kharisiri. La solución terapéutica del mal del kharisiri suele acompañarse por la intervención del yatiri en la recuperación de estas "sombras" (Fernández 2000, 2004b).

22 Wayruru. Abrus prescatorius (Girault 1987:236-237).

23 Altamisa. Ambrosia peruviana (Girault 1987:444).

24 Andres waylla. Cestrum hediondinum (Girault 1987:388).

25 Qutu-qutu. Existen dos opciones recogidas por Girault. Baccharis sp. (Girault 1987:433); Notholaena surea (Girault 1987:107).

26 "Suelda que suelda". Dendrophthora ramosa (Girault 1987:163).

27 Las muertes repentinas, sin causa aparente, se atribuyen mayoritariamente al quehacer del kharisiri. La presencia latente y la amenaza que dicho personaje ocasiona, canaliza las explicaciones más convincentes en los decesos inesperados, particularmente los que acontecen en el mes de agosto.

28 La presencia de los kharisiris y similares en épocas de crisis de los Estados modernos que generan situaciones de pánico en las poblaciones andinas, parece una constante, así lo muestra tanto el impacto del terrorismo de Sendero Luminoso en los años ochenta en El Perú, como la crisis provocada por el cólera en Bolivia en 1991 (Spedding 2005). ¿Cabe pensar en nuevas formas y perfiles de los kharisiris aymaras tras el triunfo de Evo Morales en las recientes elecciones generales de Bolivia?

Con respecto a la última cita bibliográfica tengo que indicar que el libro de Alison Spedding, publicado en La Paz en julio de 2005, es bastante posterior a la presentación inicial del presente artículo al comité editor de la revista. El libro de Spedding aporta relevantes informaciones etnográficas y metodológicas sobre el complejo del kharisiri en el departamento paceño que espero utilizar en una monografía específica que estoy elaborando sobre el kharisiri.

29 En el asunto de la identidad colectiva aymara y su defensa, recordemos que el talismán más eficaz contra los desmanes del kharisiri es la "carne de ombligo", es decir, el conector orgánico con la madre y la memoria histórica del grupo, el vínculo primario con la identidad social y las pautas sociales, sus usos y normativas, frente a los abusos y los cambios promovidos por el kharisiri. Por otro lado, los restos de la bolsa amniótica forman parte de los restos empleados por el kharisiri para hacer dormir a sus víctimas; es decir, la capa orgánica de grasa que cubre al feto y que es rota con el alumbramiento, deja al recién nacido a merced del ambiente externo; así como el cordón umbilical une al nacido con la madre y su componente social, la bolsa amniótica una vez "rotas las aguas" cesa de cumplir su misión protectora para dejar al niño vulnerable frente al medio, lo externo, el ámbito donde se mueve a sus anchas el kharisiri; por otro lado, el niño ha permanecido en posición fetal, recostado en el interior de la madre en el seno 
del saco, como si estuviera dormido, aplicación directa del efecto que el kharisiri pretende producir en su víctimas. La grasa y carne de placenta constituyen parte de los ingredientes con los que se elabora la medicina contra la dolencia del kharisiri.

30 Así lo recoge Alison Spedding (1996b:273), para los Yungas de La Paz. Henrique Urbano (1988) recoge la existencia de una imagen de niño asociado a la figura del ñakaq; se trata del Niño-Ñakaq de la iglesia del Arco de Ayacucho en el Perú. Imagen de un Niño Jesús con un cuchillo en la mano y cuya fiesta se celebra el día de Todos los Santos.

31 En este sentido, el kharisiri no está muy lejos de otra figura característica de la ciudad de La Paz y de algunos núcleos urbanos aymaras, muy identificado con el "cholo" de cultura mestiza; me refiero a la tradición del Iqiqu, celebrado en la fiesta de las alasitas de La Paz, el 24 de enero. Se trata de un enano gordo que representando a un mestizo porta toda una serie de objetos sobre su espalda que son los deseos e ilusiones de la gente hechos miniaturas; unos son marcadamente indígenas, otros característicos de las sociedades urbanas criollas y representantes de la modernidad (televisores, autos, computadoras, ,etc.). En el caso del Iqiqu se trata de objetos deseados por sus devotos que pretenden prosperar en sus negocios, con la intermediación del giboso enano; el kharisiri , sin embargo, no ofrece productos deseados por los pobladores del altiplano, sino que los impone a costa de la propia vida de los pobladores aymaras (Fernández Juárez 1998a:147-166).

32 Se achaca a los jóvenes la pérdida de pautas tradicionales y la dificultad de mantener obligaciones como los cargos ceremoniales, por su escasa responsabilidad e implicación en la vida comunitaria. Los jóvenes aymaras de los sectores próximos a La Paz acuden a la ciudad después de realizado el servicio militar con la intención de encontrar un futuro alternativo a lo que saben les espera, junto a su familia, en el dominio rural.

33 Así me lo hizo saber una mujer de la élite boliviana al conocer mi intención de desplazarme a la localidad de Achacachi, advirtiéndome del peligro que suponía convivir con esas "hordas de caníbales". La historia del sector de Achacachi constituye un ejemplo de lucha y resistencia comunitarias, lo que les ha valido una propaganda nefasta entre las clases pudiente paceñas (Albó 1979). Otro ejemplo de la mutua desconsideración entre médicos y yatiris, respectivamente considerados como kharisiris y brujos en el dominio de la salud, es el realizado por Jaime Zalles (1999:229-241). 